ConNotas. Revista de crítica y teoría literarias / Vol. V, Núm. 9 / 2007

\title{
El juego de la representación o de la simulación en Ciudades desiertas de José Agustín
}

\author{
Cecilia Eudave*
}

Resumen:

El artículo estudia la simulación como la forma en que los personajes se liberan y protegen psicológicamente a sí mismos antela presencia de un "otro", extranjero, que se arroga una posición superior. La simulación en la novela es estudiada con relación a la actuación teatral, la formulación mexicana de chistes o bromas, la literatura como institución de entretenimiento y la televisión vista como una fuerza impositiva para la trasmisión de los valores del "otro".

Palabras clave:

Representación, simulación, alteridad, subalteridad, humor, influencia televisiva, Ciudades desiertas, José Agustín.

En la novela Ciudades desiertas ${ }^{1}$ el juego de la representación o de la simulación se sitúa como elemento revelador de algunos de los juegos textuales que se dan a nivel de las estructuras. Este vertiginoso

${ }^{*}$ Universidad de Guadalajara.

${ }^{1}$ Breve sinopsis de la historia: Eligio va a los Estados Unidos a recuperar a su esposa Susana, quien tras haber recibido una beca como escritora en ese país, lo abandona. La narración nos muestra la manera en que Eligio vive, sufre y percibe la vida norteamericana que lo rechaza y señala "por su apariencia de indio irreversible", mientras intenta desesperadamente restablecer su matrimonio. Narra cómo este matrimonio mexicano se enfrenta no sólo a su conflicto como pareja sino a un conflicto cultural e identitario frente a un país que los abruma con su tecnología y sus 
uso de la representación, de la apariencia, se vuelca en el texto como una sistemática importante que constituye un buen punto de análisis. En este trabajo trataremos de abordar algunas de las maneras en que la representación marca al texto y los resultados que se desprenden de esta modalización en el relato. Para ello la instancia narrativa ha escogido diferentes líneas de acción tales como el teatro, la literatura, el chiste o la broma, la televisión para observar cuáles son sus intenciones focalizadoras, los códigos de las significaciones y los trazados que impone a la novela.

El teatro: la realidad manifestada. La presencia de la práctica teatral en el texto es constante. Existen alusiones a piezas, directores, actores famosos, e, incluso, el personaje principal, Eligio, tiene como profesión la actuación. Todo esto hace del apartado uno de los más significativos. En Ciudades desiertas simular y representar son dos acciones, dos modos de deformar o de mostrar la realidad. Pero ¿qué entenderemos por simular? ¿Qué por actuar? Tomemos como punto de referencia y de partida lo que Octavio Paz dice al respecto:

La simulación es una actividad parecida a la de los actores y puede expresarse en tantas formas como personajes fingimos. Pero el actor, si lo es de veras, se entrega a su personaje y lo encarna plenamente, aunque después, terminada la actuación, lo abandone como una serpiente a su piel. El simulador jamás se entrega y se olvida de sí, pues dejaría de simular si se fundiera con su imagen. Al mismo tiempo, esa ficción se convierte en parte inseparable de su ser: está condenado a representar toda su vida, porque entre su personaje y él se ha establecido una complicidad que nada puede romper, excep-

costumbres de consumo. Susana vuelve a abandonarlo ahí en Estados Unidos y huye con su amante polaco. Eligio entonces decide volver a buscarla, ahora él también con una amante estadounidense, y recorre en auto algunas ciudades de los Estados Unidos con el fin de encontrarla, al tiempo que describe la tristeza, desolación y homogeneización que descubre a su paso en esas ciudades desiertas. 
to la muerte o el sacrificio. La mentira se instala en su ser y se convierte en el fondo último de su personalidad. (37-38)

En la diégesis, ambas están presentes y son encarnadas en los dos personajes principales: Eligio, actor en la historia y Susana una escritora. Ellos constantemente estarán oscilando entre la actuación y la simulación. Analizo una cita de la novela para ilustrar el fenómeno:

Está bien, concedió Susana alzando el rostro y conteniendo las lágrimas, tú y yo vamos a pararle ya al Gran Teatro del Mundo. Estás actuando Eligio, no te hagas el caballero sereno y sensato; en el fondo quisieras que en vez de pared de pronto apareciera un teatro lleno de gente [...], y que todo mundo se soltara aplaudiéndote. Qué te pasa, si ya tenemos público, comentó Eligio, señalando la cocina con la barbilla. Además, yo no estoy haciendo teatro. (63)

En el ejemplo anterior, se observa cómo Susana intenta detener la representación y tomar consciencia de la realidad: "tú y yo vamos a pararle al Gran Teatro del Mundo". Sin embargo, la instancia narrativa la reviste, en su descripción, de cierto aire actoral: "alzando el rostro y conteniendo las lágrimas". Esa puesta en escena de sus conflictos y el reconocimiento de la teatralización de los mismos, supone un intento por desenmascarar, o buscar la autenticidad (lo verdadero) dentro de la apariencia (lo falso) del otro: "Estás actuando Eligio, no te hagas el caballero sereno y sensato". Si se recrimina el hecho de intentar ser un caballero que cualitativamente es superior a Eligio, es porque éste no es un caballero de "verdad". La carencia obliga, entonces, al personaje a simular, que no a actuar, "yo no estoy haciendo teatro", porque pretende ser lo que no es: sereno y sensato pero asumiéndolo como algo propio.

La recriminación y el intento de poner fin a la mascarada continúa. Susana sigue utilizando el discurso teatral para evidenciar la falsa postura de Eligio: "En el fondo quisieras que en vez de pared de pronto apareciera un teatro lleno de gente... y que todo el mun- 
do se soltara aplaudiéndote". Esto representa el deseo de una salida idílica: gente en vez de pared (reconocimiento en vez de indiferencia o rechazo) y la necesidad de recurrir a la representación para fortificar las carencias. De este modo, si se es convincente, se obtendrá del otro (en este caso lo femenino) la aceptación avalada por un público que mira lo representado. Esta búsqueda de reconocimiento llevará a Eligio a confundir en sus actos y acciones, la realidad y la apariencia, la verdad y la mentira. La simulación llegará a ser parte intrínseca de él, porque desde que llegó a los Estado Unidos: "había decidido que para lidiar con su esposa y por extensión con los gringos, tenía que ser muy firme y no dejar que nadie abusara de él” (33). El mejor escudo, para el mexicano, es la máscara, ${ }^{2}$ y Eligio la asume como simulador, pues le queda claro que en ese país no debe de perder de vista lo que busca (a su esposa) y lo que es: un macho que no pudo ser abandonado allá en la ciudad de México, cuyo orden fue quebrantado y a quien debe recuperar incluso en un territorio que lo ve como ajeno, que le demanda no perder de vista su condición de extranjero.

Eligio, entonces, ya no puede obrar de otra forma que bajo la exageración, que al ser exacerbada, se vuelve puro teatro, el personaje Eligio se confunde y se pierde, se vuelve actor de su propio drama, pierde de vista lo que es y lo que desea, perdiendo la compostura dejando de ser el caballero sereno y sensato: "procedió a golpear la puerta. ¡Sal de ahí, Susana Carne y Demonio! ¡Sal inmediatamente!... ¡Sal o te vas a a-rre-pen-tir, agregó, punteando cada sílaba con un puntapiés" (48). El discurso se ve envuelto del tono dramático: "Susana Carne y Demonio", de una postura actoral que revela su enmascaramiento "punteando cada sílaba con un puntapiés”. El sufrimiento se ve matizado por la representación; el exceso recubre la carencia, oculta la vulnerabilidad.

2 “"...] el mexicano se me aparece como un ser que se encierra y se preserva: máscara el rostro y máscara la sonrisa. Planteando en su arisca soledad, espinoso y cortes al mismo tiempo, todo le sirve para defenderse: el silencio y la palabra, la cortesía y el desprecio, la ironía y la resignación” (Paz 26). 
Susana, el otro personaje principal de la historia, también recurre a la apariencia. El uso que hace este personaje de la representación es un medio para llegar al fin. Ella no actúa, simula siempre, pero no porque quiera el reconocimiento, la aceptación, como Eligio frente a los otros, sino porque busca su liberación, su autonomía. Susana simula todo el tiempo con Eligio, con sus compañeros del "Programa de Escritores", con los organizadores, con su amante polaco. Ella, desde el principio de la novela, toma conciencia de sí y de su confinamiento, pues ha estado bajo una sujeción:

Sabía con exactitud que iría sola a los Estados Unidos y que, para evitar escenitas, lo mejor era no decir nada a Eligio. Se hallaba llena de energía, segura de sí misma y con deseos de hacer cosas. Era imposible precisar en que momento todo se había ido cubriendo de veladuras finísimas, casi imperceptibles, que la aislaban herméticamente de la realidad y que poco a poco fueron envolviéndola hasta momificarla. Susana sabía que en el fondo estaba exagerando, pero le gustaba mucho la idea de haber estado llena de vendajes. (13)

De esa sujeción "veladuras finísimas", "aislaban herméticamente", "envolviéndola", "momificarla", "vendajes", surge una revelación que se da por el conocimiento: "sabía con exactitud", "segura de sí misma", "sabía que en el fondo", de la situación en la que se encuentra: aislada de la realidad (la ficción).

Encontramos que la simulación o la actuación se presentan en el texto como vías de acceso para el reconocimiento de los otros y para la liberación. En ambos casos la búsqueda de una definición propia nos arroja a plantear un problema de identidad, que abundaremos más adelante.

\section{La literatura: Un espectáculo utilitario}

Durante el transcurso de la historia encontraremos que la literatura se presenta como un espectáculo, un show, un divertimento, un jue- 
go en el que los escritores del "Programa" se ven involucrados como actores o público. El "Programa de Escritores" se convierte así en una plataforma de espectáculos para divertir a sus benefactores. Como lo demuestra esta cita donde los escritores son invitados a la casa de la "Rica Dama Escritora que Apoyaba el Programa":

Rick avisó que comenzaba la animación y con grandes rugidos pidió que todos se concentraran en torno a él. Primero lo hicieron los que soportaban los trajes típicos de sus países, después los demás participantes y al final los ancianos millonarios que miraban todo con aire aburrido y condescendiente. Rick y Wen pidieron, que para animar la fiesta, se entonasen canciones de cada país. (121)

Es interesante señalar los atributos de los benefactores a los cuales el "Programa" se ve obligado a distraer, a devolver con diversión sus contribuciones. En primer lugar, está la anfitriona cuya numeración cualitativa (con mayúscula cada vez que se inicia una palabra) no deja de llamar la atención. Ella es primero Rica, por consecuencia Dama, luego Escritora y por ello Apoya al Programa. Esto pone de manifiesto las prioridades para destacarse: el poder económico antes que su carácter genérico, intelectual y filántropo. En cambio en los escritores del "Programa" debe destacarse, no sus cualidades literarias, sino su calidad de extranjeros y su diferenciación: trajes y canciones típicas de sus países. Ellos son una representación más o menos estereotipada del país que representan. Sus rasgos más sobresalientes no están dados por las cualidades propias de un escritor (intelectualidad) sino por su apariencia: "el egipcio lucía una túnica blanca de grandes rayas e inscripciones; los chinos se habían puesto complicadas combinaciones de telas satinadas y mocasines muy lucidores; el nigeriano vestía otra túnica, sólo que dorada" (121).

La representación a la cual son sometidos tiene la finalidad de animar a los potentados estadounidenses "senior citizens" (121) ancianos y millonarios, aburridos y condescendientes. La degradación es evidente, los extranjeros son vistos como bufones: el egip- 
cio cantó, los chinos cantaron. Bufones al servicio de una clase social selecta y específica de los Estados Unidos: los "senior cititzens" (personas mayores con alto poder adquisitivo). La agresión de la que son objeto no pasa desapercibida, los latinoamericanos intentan tomar revancha satirizando aquel intento de espectáculo internacional:

¡Qué cante Hércules!, gritó Eligio, de repente. ¿Quién?, pregunto Rick. Hércules, esta cosa colombiana. No jodas mexicano, dijo Hércules en español y sin perder la sonrisa. ¡Sí! , pidió Edmundo y lo apoyó Ramón: ¡que cante y que baile! ¡Y que se encuere!, añadió Eligio, ¡Que nos haga un estriptís para que no se aburran los senior citizens! (123)

Los extranjeros pretenden con esta insubordinación, como en muchas otras a lo largo de la novela, ejercer y mostrar su descontento ante la degradación de que son objeto: Parodiar lo que ellos ven como una farsa, vulgarizar lo que los vulgariza. Pero los códigos que utilizan para ello son ajenos a los otros, ese discurso irónico: "¿Qué se encuere! ¡Que nos haga un estriptís para que no se aburran los senior citizens!" queda entre ellos mismos. Las diferencias de idioma y de posición social (lo alto vs. lo bajo) se instituyen como una enorme barrera, lo único que consiguen es un extrañamiento y disgusto pasajero entre los ricos estadounidenses:

Mucha ropa, mucha ropa! gritaba Eligio en español y los ancianos lo miraban con curiosidad, ¿qué dice?, se preguntaban, ¿miuscha roupa? Probably he wants him hanged with a rope or something... Hércules, con meneos bien ensayados, empezó a quitarse el saco marinero [...] las expresiones de los ancianos dejaban la condescendencia y empezaban a mostrar disgusto. (123-124)

Otro tipo de deformación de la visión tradicional de lo que compete al campo de la literatura son las lecturas o tertulias literarias. El "Programa", año con año, convoca a escritores a compartir, con los participantes y estudiantes de la Universidad de la Arcadia, su 
experiencia de creación. En esta ocasión traen a Bill Murray, "porque Murray era el ídolo de muchos de los más jóvenes miembros del taller de la Universidad" (115). El escritor es calificado como "ídolo" palabra que se integra más a un registro discursivo del mundo del espectáculo: estrellas de rock, de cine. Y continúa esta focalización del discurso presentando al poeta como un artista del performance en escena:

Nadie quedó defraudado con el espectáculo de Murray, quien dijo sus poemas con acompañamiento de maracas, güiro, tumbadora y bongos, con proyecciones de big close-ups de películas pornográficas e incluso con estratégicas fanfarrias que sonaban increíblemente limpias y nítidas gracias al excelente equipo de sonido de la biblioteca. Murray se había vestido con visor de natación al cual se conectaban dos pequeños tanques de oxigeno, porque, como dijo dalísticamente, sus poemas eran muy profundos. En un momento estuvo a punto de bajarse el traje de baño: no lo hizo del todo, pero sí se empino de espaldas al público y mostró su culo. (115-116)

La satisfacción nace no por la calidad literaria de los poemas, sino por la ambientación, la escenificación. Son las maracas, el güiro, la tumbadora y los bongos, las proyecciones de tipo pornográfico y las fanfarrias "increíblemente limpias y nítidas", que no los poemas aludidos sólo al final y por una referencialidad indirecta al presentarse como "profundos", porque el escritor va vestido como buzo. Al término de esta apoteótica lectura literaria, el cierre del espectáculo se da mediante un gesto irreverente que es celebrado: "se empinó de espaldas y les mostró su culo". El culo es la parte oculta del ser, la otra cara. La cara "animal y sexual". Al mostrar el culo a alguien, esa parte púdica por imposición social, intenta librase de la sujeción y aspirar a una autonomía. Aquí, dentro de esta escenificación, de esta lectura literaria, de esta ficcionalización, el culo encuentra cabida y se descubre; en la realidad (la sujeción) sería imposible. Así el acto de enseñar el culo pierde "autenticidad" porque se da en el entorno de la apariencia y forma parte de una 
representación. Mostrar el culo en ese contexto, entonces, ya no es una agresión directa, o una liberación, se vuelca en una actuación que no convence del todo. Genera risas entre el público que mira aquello: "Está diciéndonos que somos unos culos, agregó Ramón cuando amainó la risa. Unos culeros, querrás decir, corrigió Eligió. Por eso nos muestra el culo. ¡no digas!, rió Edmundo!” (116). Esta risa condena al culo y a su mensaje, trata de restarle su carácter de agresividad. Sin embargo, ellos no se asumen como culos (agresivos) sino como culeros que en México tiene la connotación de miedosos, temerosos.

Después de detenernos en estos ejemplos, encontramos que la literatura, la creación literaria, se desmitifica, se expone como un objeto que debe proporcionar entretenimiento. Este enfoque reduccionista profana el sentido de la misma y la deconstruye. Lejos de ser la literatura un arte "inútil", se vuelca sobre una filosofía utilitarista donde la palabra clave es el interés. Así la literatura es juzgada desde el punto de vista de su utilidad, de su rendimiento. Recordemos que el "Programa" es "una cómoda y bien remunerada forma de ganarse la vida" (86). La seriedad, la formalidad, también es descalificada y se sustituye por la diversión, existe una analogía entre show y literatura, entre espectáculo y creación.

\section{La práctica del chiste y de la broma}

En la novela que nos ocupa encontramos varias referencias al chiste o la broma. Esta representación de la realidad, con su tono de burla y su sarcasmo, revela muchos de los miedos, de las dudas, de los resentimientos de los personajes del texto. Traza una manera particular de enfrentamiento entre el yo (mexicano) y el otro (los extranjeros). ¿Por qué un enfrentamiento? Porque "pretende disminuir al otro, ofenderlo si detenta el poder, la fuerza, el dinero, la posición política, la dignidad derivada del talento, de la capacidad creativa" (Aramoni 102). 
¿Qué es el chiste? El chiste, para el mexicano, es un modo de agresión que desvaloriza el objeto de su burla. Este discurso distorsionado, vulgar a veces e irónico, pretende decir lo que de otra forma no se podría, por miedo a la represión, a la violencia y al castigo. Como si en México "sólo pudiera criticarse por medio del chiste y no de modo abierto y franco, como resulta habitual en otras culturas y en otros países. Significa así una especie de válvula de escape para la agresión y la censura mostrándose así la protesta y el disentimiento" (Aramoni 102-103).

Antes de analizar los ejemplos en la novela, se considera pertinente observar el funcionamiento y la intencionalidad de uno de estos chistes, y en particular un chiste-fórmula que introduce a personajes de distintas nacionalidades en situaciones extremas e ilógicas, situaciones absurdas donde ponen a prueba sus capacidades. Así ubicaremos la referencialidad directa o indirecta que se establece entre este tipo de chiste y el relato. Consideremos el siguiente chiste del tipo mencionado.

En un accidente automovilístico se mueren cuatro amigos, un francés, un alemán, un gringo y un mexicano. Llegan directo al infierno y el diablo les dice:

-Les voy a dar una oportunidad, el que me miente la madre sin que yo me dé cuenta podrá regresar a la tierra y vivir unos años más. Pero ay de aquel al que yo sorprenda, porque entonces se quemará en el infierno por el resto de sus días. Entonces el francés se la mienta con el pensamiento: "Malditó diabló veté mucho a la chingadá". Y el diablo le dice:

-Ah, conque con el pensamiento, ¿eh? Te rostizarás en el infierno por el resto de tus días.

$\mathrm{Y}$ el francés desaparece.

-El que sigue -dice el Diablo.

Y el alemán contesta:

-Herr Diablo, mira lo que está detrás de ti.

Y cuando el Diablo se voltea, se la mienta con el brazo. El Diablo entonces habla:

-Ah, conque mentándomela con señas, ¿eh? Te rostizarás en el infierno por el resto de tus días. 
El alemán desaparece.

-A ver, ¿quién sigue? -pregunta el Diablo. Entonces el gringo saca una pluma y un pedacito de papel. Escribe: "Diablo cabrón, chinga a tu madre". Y el diablo lo sorprende:

-Ah, conque mentando la madre por escrito, ¿eh? Te rostizarás en el infierno por el resto de tus días. El gringo desaparece. El mexicano, al ver esto, se adelanta y le dice:

-Oye, Diablo, te vendo un anillo en $\$ 500.00$ pesos.

-Y yo, ¿para qué quiero un anillo? Él le contesta.

-Espérame tantito, deja te explico. Tú se lo puedes vender a tu mamá en $\$ 1,000.00$ pesos, y ella se lo puede vender a quien quiera en $\$ 1,500.00$ pesos.

-Y eso, ¿para qué? -le responde el Diablo contrariado.

-Pues así chingo yo, chingas tú y ¡Chinga tu madre!

El chiste anterior nos muestra un sentido de humor burdo, crudo y cruel, a juzgar por los elementos y por cómo se burla de la tragedia (la muerte, el infierno). Este tipo de chistes lleva una intención: vencer, derrotar al contrincante exponiéndolo. El otro no puede ser mejor que él. En el ejemplo anterior, las fuerzas mundiales encarnadas por Francia, Alemania y Estados Unidos, al igual que una fuerza sobrenatural, la del Diablo, se ven disminuidas por el uso del ingenio. El mexicano logra salir adelante enfatizando su capacidad de improvisación, su astucia. Pero es una guerra idílica la que él gana, una guerra ficticia que sólo puede brindarle una satisfacción nihilista. Como en el carnaval, la inversión de los papeles es perenne, transitoria, los poderosos pueden dejar de serlo por unas horas y los otros tomar su lugar. La fórmula del chiste no deja de arrojar a la cara una realidad metafórica, realidad que sólo existe en la invención, en la imaginación. El mexicano es un vencedor ahí porque no puede competir en otros niveles con las naciones implicadas. Las que él cree el centro del mundo. Así, las desplaza por medio del chiste, se libera de su frustración, humillándolos. Los personajes de estos chistes-fórmula (donde pueden existir tantas situaciones como creatividad) siempre son anónimos: un francés, un alemán, un gringo, un mexicano, puede ser cualquiera. Esto per- 
mite fabricar la burla sin comprometerse, evitando un enfrentamiento directo y sus consecuencias. Así,

esta actitud no es constructiva y no produce otra cosa que regocijo y cierta alegría. Se emplea el ingenio, sutileza, penetración y un poco de poesía para algo destructivo... se disminuye una actitud, una persona, un esfuerzo, un logro; no se da nada a cambio, no se sustituye al proponer un cambio, una modificación, una mejora. (Aramoni 104)

Manejo del chiste y de la broma en el texto Ciudades desiertas. En la novela encontramos muchas alusiones directas al chiste y a la broma, como en este ejemplo:

Entre risas, Eligio comentó que el Programita le recordaba aquellos viejos chistes de niños en los que había un francés, un ruso, un gringo, un alemán y un mexicano. ¿Sí? Con la diferencia que aquí no encontrarás ni un francés, ni un inglés, ni un alemán, ni siquiera un español, porque esta gente trae puro escritor de países raspa, las naciones de piojito, el good ol' tercer mundo. (88)

En la cita anterior podemos notar lo popular como punto de referencia a sus observaciones que se basan en el chiste. El discurso degradatorio se inicia desde el uso de un diminutivo "el Programita", que, lejos de aludir a un recuerdo positivo, se enfrenta al chiste ya revestido de cierta despectividad. ${ }^{3}$ Además, estos chistes son viejos e infantiles, dos elementos más que inciden en degradar sobre lo degradado. Eligio emite este juicio entre risas. Después toma la palabra Susana para enfatizar la diferencia entre ese "chiste fórmula" dentro de una realidad metafórica o idílica que sólo se

${ }^{3}$ La novela se escribe en 1982, año en que las principales potencias son, desde la perspectiva mexicana: estadounidenses, rusos, alemanes y franceses. Los rusos después desaparecieron del panorama de los chistes, y entraron a ocupar su lugar los chinos. 
puede dar en una situación tan absurda como la de los chistes (ficción), y la realidad de la situación de los autores involucrados: segregados. Esta toma de conciencia de la diferencia: "con la diferencia de que aquí no encontrarás ni un francés, ni un inglés, ni un alemán, ni siquiera un español' nos sitúa en dos espacios diferentes: un allá (la realidad representada metafóricamente, ficcionalizada), donde eso puede funcionar, y un aquí (la realidad "verdadera"), donde todo vuelve al orden. Los países implicados en este ejemplo son primermundistas, de Europa central, salvo Estados Unidos, y hasta los españoles, considerados por la instancia narrativa como no dignos de ese rango ("ni siquiera un español"), forman parte de este grupo de "élite". Porque Estados Unidos sólo "trae a puro escritor de países raspa, las naciones de piojito, el good ol'tercer mundo (otra deformación del lenguaje se refiere al good allold)". El proceso de degradación continúa ya en la realidad "verdadera" del texto, no afectando al "Programa", sino incidiendo sobre los extranjeros cuyos países son "raspas" (corrientes), son naciones de "piojito" (sucias, pobres), el good ol' del tercer mundo (lo bueno del tercer mundo). Aunque el discurso está cargado de ironía, no dejan las dos instancias implicadas, los extranjeros de élite (lo alto) versus los extranjeros de tercera (lo bajo), de ser rebajados. Sin embargo, debe tomarse en cuenta que los espacios de la degradación no son los mismos. Mientras que los extranjeros de élite son disminuidos en un espacio metafórico y caricaturesco (el chiste), los otros lo son en el espacio real del texto.

A lo largo de la historia, la referencia a las bromas para enmascarar los miedos (la ocultación) y para desprestigiar al otro y restarle seriedad es una constante. Considérese el siguiente pasaje:

Las declaraciones no son asunto de broma, advertía un letrero junto a la caseta de revisión de rayos equis [...] a cada viajero que sale se le pregunta si no lleva armas de fuego, y no faltan los bromistas, me temo que sobre todo gente de nuestro programa, que dice que sí, y los agentes de seguridad se los llevan y los hacen pasar un muy mal rato, aunque sepan que todo era una broma. (16) 
El sentido del humor de los extranjeros llega a tal grado que se necesita de la advertencia y del castigo. Las bromas (caos) no tienen cabida para el otro que ve su entorno formalmente, que cuida de su apariencia (el orden). La desestabilidad viene precisamente de la broma que orilla a la duda. Esta duda genera una violencia ("hacen pasar un muy mal rato") que se escuda en la violencia de esa arbitrariedad (si traemos armas de fuego), de ese imprevisto que no respeta el orden establecido y agrede con la falta de seriedad. En el texto Ciudades desiertas podemos localizar cómo la representación de la realidad del texto que agrede y degrada trata de enmascararse mediante el uso catártico del chiste o la broma, para hacer de ello un juego y restarle seriedad. Se abandona al espacio de ficción y así: "Sustituye su ser auténtico por el de un personaje ficticio que representa en la vida, creyéndolo real. Vive, pues, una mentira, pero sólo a este precio puede liberar su conciencia de la penosa idea de inferioridad" (Ramos 14). Por ello se busca la similitud en un espacio metafórico que no logra sacarlo del estatus preestablecido por la instancia narrativa: ser segregado (el rechazo). De esta manera los esfuerzos por encubrir la realidad son sólo actos fallidos, que aligeran brevemente la existencia del individuo, porque "el mexicano se ha encontrado históricamente enfrentado a una contradicción: una gran desproporción entre lo que quiere hacer y lo que puede hacer, la que lo lleva inevitablemente al fracaso y al pesimismo" (Bartra 91).

La televisión: representante de la sujeción y del control estadounidense. La televisión es uno de los medios de comunicación de mayor importancia en los Estados Unidos, y por extensión, en todo el continente americano. Las cadenas televisivas, con sus noticieros, talk shows, programas de concursos, teleseries, etc., modelan muchos de los aspectos de la vida cotidiana de la sociedad. Se instituye esta práctica como uno de los aparatos ideológicos más fuertes para el sistema. Es la televisión el mejor difusor del pensamiento y el modo de vida del estadounidense, tiene un valor ontológico superior al de cualquier otra cosa. La televisión, en Ciudades desiertas, es una presencia inagotable, una sombra que está ahí todo el tiempo: 
¿Y eso?, preguntó Susana fríamente. Es una televisión, informó Becky. Claro, pero, ¿qué hace aquí? El Programa proporciona aparatos televisores a todos los participantes. Pero yo no quiero una televisión, replicó Susana, jamás he tenido una y no creo que me vaya a convertir en adicta sólo porque he venido a Estados Unidos. De cualquier manera te sugeriría que te quedes con ella, dijo Becky, quizá te sea útil en algún momento de hastío. No es necesario, insistió Susana, es mejor que se la lleven, no la quiero. En ese caso, respondió Becky yendo a la puerta, la dejaremos allí, y si no quieres verla simplemente no la enciendas y ya. (19)

Algo tan concreto como la televisión es calificado de entrada por Susana como "eso", lo cual le resta definición y le confiere un carácter de indefinido. Sin embargo, "eso" inmediatamente es devuelto a su orden natural: "es una televisión", informa Becky, e informar implica en cierto grado instruir. El enfrentamiento entre Becky y Susana entonces se establece como un duelo. Susana hace uso de la repulsión y exclusión del aparato: "no la quiero" (dos veces), “mejor que se la lleven”, “jamás he tenido una”. Enfatiza su inutilidad y su carácter nocivo: "No es necesaria", "no creo que me vaya a volver adicta sólo porque he venido a los Estados Unidos". La argumentación de Susana sería válida en su contexto (México), pero en Estados Unidos no lo es. Becky se encarga de que la imposición velada ("te sugeriría que te quedaras con ella") se justifique por su carácter de utilidad y divertimento: "quizá te sea útil en un momento de hastío", porque la televisión te incluye en una comunidad (colectividad versus individuo) y te vuelve homogénea: "El programa proporciona aparatos televisores a todos los participantes". Y porque ella debe estar abi como una presencia insuprimible, como una parte intrínseca del decorado: "la dejaremos ahí, y si no quieres verla simplemente no la enciendas y ya".

Más adelante en la historia encontramos otro ejemplo que sitúa a la televisión como un agresor, y como un acto que conlleva el descenso. Eligio, después de examinar el departamento de Susana en Estados Unidos, exclama: 
¡Y una televisión! No es posible, pensó Eligio, yendo al pequeño aparato blanco; qué bajo ha caído esta chava. Era Sony. Sony honey if you wanta get along with me! La encendió, y en la pantallita, a todo color, apareció la pesadillesca exposición de un locutor, con traje de etiqueta, que anunciaba cerveza Budweiser, y después de una sucesión de efectos lumínicos surgió la amable figura de Mae West. Qué buena onda, pensó Eligio, y ya se había recostado en la cama para ver la película. (46)

Eligio reacciona de la misma forma que Susana ante la presencia de la televisión: "no lo puede creer". El rechazo y la sorpresa van seguidos de una degradación: "qué bajo ha caído". Este descenso continúa en diferentes niveles: Susana es baja porque tiene televisión, este último es un apartado decadente y además está en el suelo. Por si no fuera suficiente, la marca es Sony (dos veces), una de las multinacionales más importantes que han llenado de aparatos televisivos el mundo. El segundo Sony del ejemplo también hace referencia a una forma afectuosa de llamar a un hijo, Sony es hijito. La sentencia en inglés que le sigue: "Honey if you wanta get along with me" (cariño, si quieres pasártela conmigo) completa el sentido de la oración. La televisión asume una función de paternidad respecto a sus espectadores. Una última observación sobre esta frase: ella es una desconstrucción de la canción "Money, honey", interpretada por Elvis Presley, otro de los íconos de la cultura estadounidense. A diferencia de Susana, quien ignora la televisión totalmente, Eligio la enciende. Lo que arroja a sus ojos son imágenes de pesadilla "exposición de un locutor, con traje de etiqueta, que anunciaba cerveza Budweiser". Esta asociación de pesadilla con la televisión está dada por la aparición de un estereotipo estadounidense: el locutor-presentador de programas, que tiene como función promocionar productos de alto consumo nacional, en este caso la cerveza Budweiser. Esa imagen pesadillesca es sustituida después por otra, que "surgió" del mismo aparato: "la amable figura de Mae West". Esta sustitución atrapa a Eligio, su rechazo anterior se convierte en aceptación inmediata: "Qué buena 
onda", para después recostarse y ver la película. Este ejemplo maneja dos niveles distintos sobre la percepción del personaje Eligio y la televisión. Mientras el aparato televisivo represente los valores convencionales estadounidenses, se lo condena duramente, pero una vez que se han sustituido y filtrado otros registros visuales más universales (el cinematográfico, Mae West), la aceptación aparece. La televisión no es en sí un ente que agrede y rebaja, es la práctica de ella lo que la pervierte.

No es extraño que el pensamiento mexicano vea en este mass media la influencia devastadora de los Estados Unidos donde dominan los valores burgueses en contra de una cultura nacional popular en decadencia, misma que es contradictoria pues si finalmente es nacional adquiere todas las facetas propias de la dominancia y la hegemonía. Por ende:

A veces se distingue la cultura de masas de la cultura popular, de tal forma que en la primera se clasifican los efectos nocivos de la penetración de las culturas extranjeras, la homogeneización que producen los medios masivos de comunicación y la expansión de la nueva barbarie industrial y urbana; frente a esta masificación de la cultura habría que rescatar a la "verdadera" cultura nacional, cuyas raíces estarían profundamente enterrada en el alma del pueblo: un pueblo imaginario aún manchado por el fango de la televisión, la radio y el cine. (Bartra 189)

La problemática de búsqueda de integración y reconocimiento en la novela Ciudades desiertas encuentra un buen punto de apoyo en la sistemática del juego de la representación o simulación, pues los personajes son reiteradamente mediatizados por las instituciones implicadas en el texto para actuar así. Es a través de ellas y por ellas, que los personajes buscan liberarse o se protegen en la simulación, ya que "el carácter nacional-popular de la literatura mexicana contemporánea sufre una serie de precaridades, a pesar de que existe un sistema metafórico referencial y mediador de lo mexicano" (Bartra 190). 
Sistema por el cual evaluamos y juzgamos todo, la Universidad de la Arcadia es el ejemplo; la ironía está dada en su mismo nombre, en el tipo de estudiantes que asisten: hijos de trabajadores de clase media que buscan la superación, el reconocimiento de la sociedad al pasar por la institución porque "es un orgullo estar en el mejor taller de literatura del país", que además acepta extranjeros e impone sus reglas: "aquí todo el mundo te dice cómo escribir". La lucha contra la serialidad del pensamiento, el no a la retórica del conocimiento, la necesidad de nuevas formas de integración genérica y de expresión ante la sociedad, el cambio verdadero dentro de las instituciones oficiales, mueven a los personajes a simular, a fingir, a jugar con la actuación para camuflajear sus intenciones reales: ser reconocido por el otro, dejar atrás el sentimiento de inferioridad. Recuérdese a Eligio, "indio irreversible" que busca su lugar y el respeto de la sociedad extranjera y propia, al mismo tiempo que su inminente imposición genérica frente a su esposa Susana, para dejar de simular o representar, para dejar de ser el "héroe agachado" que

es fundamentalmente una transfiguración del indio y una transposición de rasgos campesinos, a su humilde nacimiento fueron convocadas importantes corrientes de ideas: el surrealismo, el psicoanálisis y el existencialismo. De allí las formas oníricas del mito, su inmersión en las aguas de la infancia y la angustia que lo tiñe. (Bartra 97)

Pero en esa búsqueda personal del yo, de su defensa, ya sea enmascarándola, ya sea simulando ser lo que el otro quiere (Lo femenino frente a lo masculino en el texto y a la inversa. Lo nacional frente a lo extranjero en la novela, la imposición de modelos culturales de consumo), hacen de la literatura y del teatro, como del chiste y la broma o la televisión, un pretexto, un juego de espejos donde estas formas son objeto y condición para acceder, por medio de ellas, a la aceptación, a la integración anhelada, y así formar parte de una alteridad que, si me reconoce, fortalece y enuncia lo propio. 


\section{Bibliografía}

Aramoni, Aniceto. El mexicano ¿un ser aparte? México: Offset, 1984. Agustín, José. Ciudades desiertas. México: Edivisión, 1982.

Barta, Roger. La jaula de la melancolía. Identidad y metamorfosis del Mexicano. México: Grijalbo, 1987.

Cros, Edmond. Literatura, ideología y sociedad. Madrid: Gredos, 1980. Paz, Octavio. El laberinto de la Soledad. México: FCE, 1989. Ramos, Samuel. El perfil del hombre y la cultura en México. México: Espasa Calpe, 1981. 